\title{
Strengthening the roadbed of highways using soil stabilizers
}

\author{
Abdubaki Kayumov ${ }^{*}$,Barno Salimova, Raykhon Khakimova, and Azizjon Kayumov \\ Tashkent State Transport University, Tashkent, Uzbekistan
}

\begin{abstract}
Modern trends in road construction (an increase in traffic intensity and carrying capacity of road transport, expansion of the network of roads, including local ones) put forward the problem of the need not only to increase the durability of road structures but also to use local materials and soils in road construction. Considering that many regions of Uzbekistan experience a shortage of materials for the construction of foundations, and their delivery is associated with additional transport costs, the relevance of using local soils in the bases of road pavements becomes obvious. Recently, there has been an increased interest in methods of physical and mechanical stabilization of soils using stabilizers. Dependence is proposed that allows one to determine the strength and deformation characteristics of stabilized saline soils.
\end{abstract}

\section{Introduction}

The problem of using saline soils in the design and construction of highways is of great importance. Saline soils are widespread along the coasts of the Pacific, Atlantic, Indian Oceans, and many seas. As the foundation of structures, saline soils are used in Australia, Egypt, India, Iran, Kazakhstan, Mexico, Pakistan, Russia, USA, Uzbekistan, as well as in some European countries. Therefore, at present, the study of the properties of saline soils, including the assessment of the stability of road embankments built from saline soils, are considered urgent tasks [1-6].

In the world in the process of design, construction, and operation of highways, scientifically grounded and targeted studies of the strength indicators of saline soils in the roadbed body are relevant. In this area, including to substantiate their design characteristics, the development of design solutions for the working layer of the subgrade from saline soils taking into account the water-thermal regime, improvement of methods for assessing the density and moisture content, properties of saline soils of the subgrade of existing highways, substantiation of the design characteristics of saline soils, improving methods for artificially improving the properties of saline soils with stabilizers, as well as developing methods for predicting their impact on the design characteristics of the subgrade is considered relevant.

\section{Methods}

*Corresponding author: abdubakigmg@mail.ru 
Saline soils include soils containing more than $0.3 \%$ by weight of readily soluble salts in the upper meter strata - chloride, sulfuric acid, and carbonate salts of sodium, calcium, and magnesium.

Soils containing in the surface layers to a depth of $1-2 \mathrm{~m}$ in a free state more than $1 \%$ of readily soluble salts are called salt marshes.

Saline soils are distinguished by external features:

- wet and crusty (blinders, litters) - salt marshes in areas with a high level of saline groundwater, on the surface of which it is dry; the salt crust appears during the season. Wet salt marshes belong to the category of soft soils, and when a road is built through them, it is necessary, as in swamps, to reckon with the sediments of the subgrade and the possibility of the foundation soil bulging out from under the embankment;

- plump, where under a thin earthy crust lies a loose layer, abounding in crystals of salts, mainly sodium and magnesium sulfates;

- taker-like, covered in dry weather with a relatively thick clay crust, broken by a network of cracks into plate-like units, which contain chlorides, sulfates, and gypsum in the soil [7-10].

Salts in the soil can attack road surfaces. Even with content of only $1 \%$, magnesium and sodium sulfate destroys coatings in two to three seasons. Low-aggressive salts $\mathrm{NaCl}, \mathrm{CaCl}_{2}$ do not destroy coatings even at a content of more than $5 \%$. Limestone coverings are more resistant than igneous rock coverings. The destructive effect of water-soluble salts on bitumen and tar is manifested in the form of leaching and emulsification, binder under the influence of salts. The most stable road pavements are built by a hot method using viscous bitumen.

The level of soil salinity in natural conditions of the territory of Uzbekistan in road embankments by region is shown in figure 1. [3-5], [14-18].

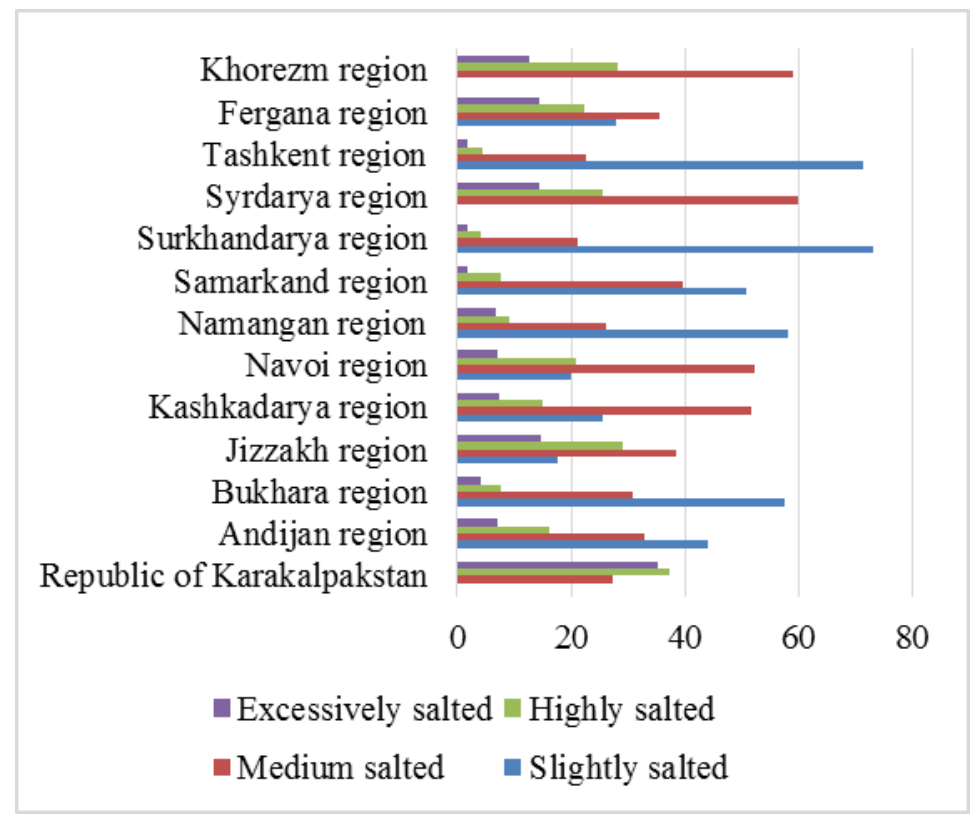

Fig. 1. The level of soil salinity by regions of the territory of Uzbekistan

\section{Results and discussion}


All methods of artificially improving the engineering behavior of soils following the main acting factors and the effects can be divided into two directions:

- physical and mechanical stabilization;

- physical and chemical transformation;

Physical and mechanical stabilization is associated with structural rearrangements in the soil under the influence of external stresses and the formation of a new structure in equilibrium with the new stress state. And also with the redistribution of the liquid component in soils.

Physicochemical transformation is associated with the formation of artificial solids that cement solid structural elements of soils [3-5], [11-13].

Recently, there has been an increase in interest in methods of physical and mechanical stabilization of soils using hydrophobic surfactants.

For artificial purposeful changes in the properties of natural clayey soils, stabilizers have recently been widely used (figure 2). [4, 10, 12], [19-21].

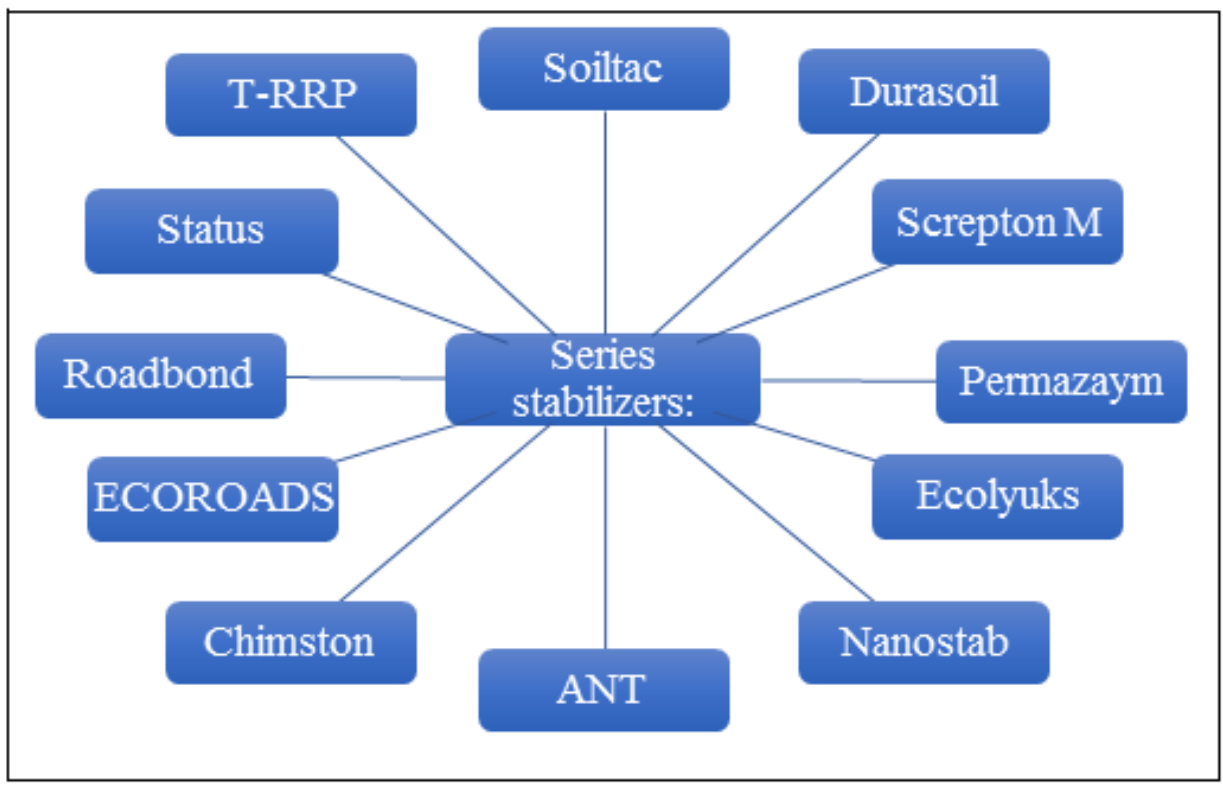

Fig. 2. Types of stabilizers

To assess the effect of "Bitumen emulsion" on the calculated characteristics of the soil in laboratory conditions, special studies were carried out. At the same time, the deformation and strength characteristics were determined.

A lever press was used to determine the value of the static elastic moduli of both stabilized and non-stabilized saline soils.

To assess the effect of "Bitumen emulsion" on the strength characteristics, that is, when determining the shear resistance of loess soils, a Maslova-Lurie device (GGP-30) was used. The GGP-30 device consists of the following units: a work table; cutter; a loading device that transfers vertical pressure to the soil sample; a lifting device of a movable panel and a mechanism for transferring a horizontal shear force to the sample to the sample [1], [7-9], [11], [22-25].

Soil compaction was performed without lateral expansion in a standard ring from a shear device. Soil samples were prepared as follows. The pre-dried soil was sieved through a sieve $\mathrm{d}=2 \mathrm{~mm}$ and moistened to $0.55,0.60,0.65,0.70 \mathrm{Wt}$. For uniform distribution of 
moisture, the moistened soil was held in a desiccator. After 24 hours, samples were prepared compacted to a density of $0.96,0.97,0.98,0.99$ and 1.0

Soil without stabilizer:

- modulus of elasticity $56 \mathrm{MPa}$

- angle of internal friction 260

- adhesion $0.24 \mathrm{~kg} / \mathrm{cm}^{2}$

Soil reinforced with stabilizer:

- modulus of elasticity $65 \mathrm{MPa}$

- angle of internal friction 290

- adhesion $0.30 \mathrm{~kg} / \mathrm{cm}^{2}$

Soil reinforced with stabilizer and cement:

- modulus of elasticity $70 \mathrm{MPa}$

- angle of internal friction 300

- adhesion $0.34 \mathrm{~kg} / \mathrm{cm}^{2}$

The following conclusion can be drawn based on the results obtained: for soils treated with a stabilizer, the angle of internal friction and adhesion increases.

As in the above experiment, the maximum density was determined on standard compaction equipment with and without the addition of "bitumen emulsion" to artificially saline soils. The research results are shown in figure 3.

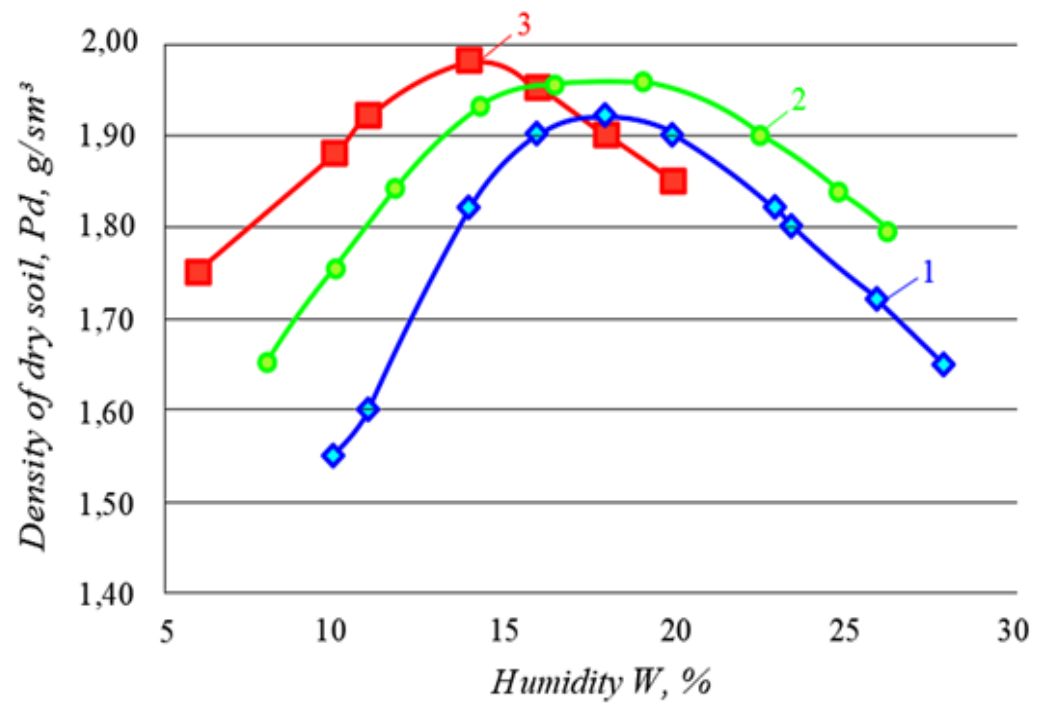

Fig. 3. Dependence of the density of dry soil on moisture with standard compaction of saline soil: 1saline soil; 2- stabilized soil; 3 -stabilized soil + cement

Experiments show that when using the stabilizer "Bitumen emulsion", saline soils decreased by $25 \%$ compared to the absence of favorable moisture, and the maximum density of dry soil increased by $6 \%$.

In laboratory conditions, using the "PR" device, the soaking of artificially saline soils with the addition of "bitumen emulsion" was determined. The result is shown in figure 4. 


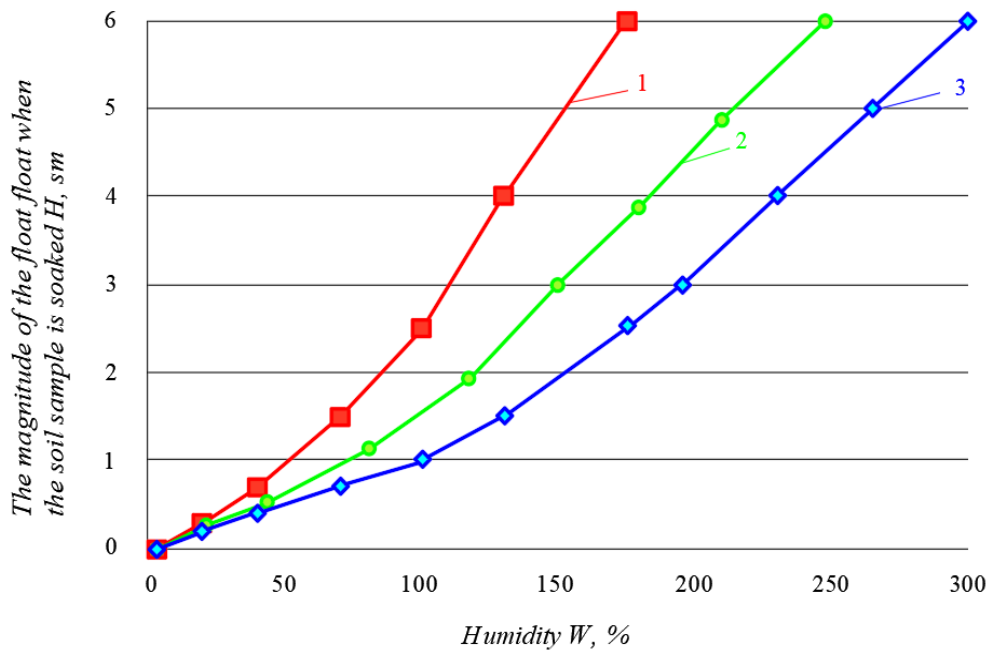

Fig. 4. Dependence of the soaking capacity of saline soil samples in water over time: 1-saline soil; 2stabilized soil; 3-stabilized soil + cement

The graph shows that the soaking of the "Artificial saline soil + bitumen emulsion" system is 2.5 times higher than that of "untreated soil".

Table 1 shows the results of laboratory studies of stabilized and non-stabilized "Bitumen emulsion" artificially salted with $5 \% \mathrm{NaCl}$ light silt sandy loam.

Table 1. Estimated indicators of artificially saline soils stabilized and unstabilized by "Bitumen emulsion"

\begin{tabular}{|c|c|c|c|c|c|c|c|c|c|}
\hline \multirow{3}{*}{$\begin{array}{c}\text { Compaction } \\
\text { factor } K_{s}\end{array}$} & \multicolumn{9}{|c|}{ Design indicators of soils } \\
\hline & \multicolumn{3}{|c|}{ Unstabilized } & \multicolumn{3}{|c|}{ Stabilized } & \multicolumn{3}{|c|}{ Stabilized + cement } \\
\hline & $\begin{array}{c}E, \\
\mathrm{MPa}\end{array}$ & $\begin{array}{c}\varphi, \\
\text { deg. }\end{array}$ & $C, \mathrm{MPa}$ & $\begin{array}{c}E, \\
\mathrm{MPa}\end{array}$ & $\begin{array}{c}\varphi, \\
\text { deg. }\end{array}$ & $\begin{array}{c}C, \\
\mathrm{MPa}\end{array}$ & $\begin{array}{c}E, \\
\mathrm{MPa}\end{array}$ & $\begin{array}{c}\varphi, \\
\text { deg. }\end{array}$ & $\begin{array}{c}C, \\
\mathrm{MPa}\end{array}$ \\
\hline 0.96 & 56 & 26 & 0.024 & 65 & 29 & 0.030 & 70 & 30 & 0.034 \\
\hline 0.97 & 60 & 26 & 0.029 & 70 & 29 & 0.036 & 76 & 30 & 0.039 \\
\hline 0.98 & 65 & 26 & 0.034 & 75 & 29 & 0.041 & 81 & 30 & 0.046 \\
\hline 0.99 & 71 & 26 & 0.040 & 82 & 29 & 0.048 & 87 & 30 & 0.051 \\
\hline 1.00 & 78 & 26 & 0.045 & 89 & 29 & 0.054 & 92 & 30 & 0.059 \\
\hline
\end{tabular}

Note: The calculated parameters of the soils were determined at a moisture content of $0.55 \mathrm{~W}_{\text {cur. }}$.

From the results of the studies shown in Table 1, it was revealed that with the compaction coefficient of the stabilized soil, the modulus of elasticity increases to $89 \mathrm{MPa}$, that is, it increases by $12 \%$; adhesion force by $0.054 \mathrm{MPa}$, that is, increased by $15 \%$; the angle of internal friction by 29 degrees, that is, it increases in the order of $10 \%$.

\section{Conclusions}

The use of stabilizers makes it possible to obtain a system of "clay soils-hydrophobic surfactant" with controlled physical properties.

The effectiveness of the use of stabilizers increases with increasing bound water in soils and will be the more, the more clay particles in the soil.

Obtaining a practical effect from soil treatment is possible only after its compaction, the degree of which will be higher than that of the original soil. 
The economic effect of the use of such systems requires monitoring and evaluation in each specific case but can reach $30 \%$ of the cost of the road due to the use of local stabilized soils, the possibility of reducing the thickness of the pavement, or increasing its durability due to the increase in the strength of the soils treated with the stabilizer.

\section{References}

1. Khudaykulov R.M. The use of stabilizers to improve the properties of cohesive soils, Tashkent, (2011)

2. Khudaykulov R.M. Design characteristics of saline soils used in transport construction, Metro and tunnels, №1, pp. 32-36 (2016)

3. Khudaykulov R.M. Justification of the design characteristics of saline soils of the subgrade, Tashkent, (2018)

4. Khudaykulov R.M. Improving the strength of the soil base roads using stabilizers. Transport problems, Poland, pp. 260-264, (2021)

5. Roads and Salinity ISBN: 0734753772, Department of Infrastructure, Planning and Natural Resources pp. 26 (2003)

6. Kayumov A.D., Khudaykulov R.M., Usmanov A. The use of stabilizers to improve the properties of soils pp. 208-211, Tashkent, (2010)

7. Kochetkova R.G. Features of improving the properties of clay soils with stabilizers, Science and technology in the road industry, № 3, pp. 23-27 (2006)

8. Sukhorukov A. V. Justification of regional calculated values of the characteristics of clay soils for the design of road pavements in the conditions of Western Siberia, Tomsk, pp. 86-90 (2017)

9. Scientific and technical report on the topic "Theoretical and practical study of the influence of different quality and amount of salts in the soil on their water-physical and mechanical properties", p. 90, Tashkent (2012)

10. Babkov V.F., Andreev O.V. Road design, p. 368, (1987)

11. Babaskin Y.G. Strengthening of soils by injection during road repair -p. 177, Minsk: UE Texnoprint, (2002)

12. Neal B.G. The Design of Piled Foundations, Edition Structures and Solid Body Mechanics, pp. 35-42, (2013)

13. Ushakov V.V., Olkhovikov V.M. Construction of automobile roads, Moskva KNORUS, pp. 157-162, 2013

14. Babaskin Y.G. Soil properties and their influence on the stability of engineering structures, p.73, BGPA: Mn (2000)

15. Fedulov A.A. The use of surfactants (stabilizers) to improve the properties of cohesive soils in road construction conditions- p. 165, (2005)

16. K. Newman, J.S. Tingle Emulsion polymers for soil stabilization. Pre-sented for the 2004 FAA worldwide airport technology transfer con-ference, Atlantic City USA, (2004)

17. Automobile roads and bridges. Construction of structural layers of pavements from soils reinforced with binders, Overview information, M. FGUP "Informavtodor", (2007)

18. Dmitrieva T.V. Stabilized clay soils KMA for road construction, p. 24, Belgorod, (2011)

19. Methodical recommendations for strengthening the roadbed shoulders using soil stabilizers, M., (2003)

20. Abramova T.T., Bosov A.I., Valieva K.E. Use of stabilizers to improve the properties of cohesive soils, Geotechnics, № 3 - 4, p. 28, (2012) 
21. Zolotykh S.N. Stabilization of clay soils in transport construction, In the collection: Education, science, production Belgorod State Technological University. V.G. Shukhova, pp. 600-603 (2015)

22. Mogilevtsev D.A., Trautvain A.I. Theoretical foundations of strengthening and stabilizing soils, Collection of reports of the IX International Youth Forum "Education. The science. Production ", Sat. reports, Belgor. state technol. un-t., (2017)

23. Akimov A.E., Trautvain A.I., Chernogil V.B. Improving the physical and mechanical characteristics of hardened soils when using stabilizing additives of the Chimston series, In the collection: Science and education in modern conditions, Materials of the International (correspondence) scientific and practical conference, pp. 49-55 (2017)

24. Trautvain A.I., Akimov A.E., Yakovleva A.A. Features of the use of stabilizing additives for strengthening soils // In the collection: Science and education in modern conditions. Materials of the International (correspondence) scientific-practical conference, pp. 200-207, (2017)

25. Yadykina V.V., Gridchin A.M., Antonova R.O. Prospects for the use of polymer stabilizers in soil strengthening in road construction, In the collection: Effective building composites Scientific and practical conference dedicated to the 85th anniversary of the honored worker of science of the Russian Federation, academician of RAASN, doctor of technical sciences Bazhenov Yuri Mikhailovich, pp. 767-770, Belgorod State Technological University V.G. Shukhov, (2015) 